\title{
Determinants of inflation in Iran based on Bayesian Model Averaging (BMA)
}

\author{
Mohsen Mehrara ${ }^{1, a}$, Arezoo Ghazanfari ${ }^{2, b}$, Motahareh Alsadat Majdzadeh $^{1,0}$ \\ ${ }^{1}$ Faculty of Economics, University of Tehran, Tehran, Iran \\ ${ }^{2}$ Power \& Water University of Technology (PWUT), Tehran, Iran \\ ${ }^{a-c}$ E-mail address: mmehrara@ut.ac.ir , arezooghazanfari86@gmail.com , \\ motysha64@gmail.com
}

\begin{abstract}
Due to the important influence of inflation on macro-economic variables, researchers pay tremendous amount of attention to its determinants. Accordingly, in the following research, the impact of 13 variables on inflation during the period of 1338-1391 by using Bayesian Model Averaging (BMA) method has been investigated for Iran economy. The ranking of the 13 explanatory variables are obtained based on the probability of their inclusion in model. The results show that the energy price and money imbalance (lagged ratio of money to nominal output) have expected and positive effect on inflation rate with a probability of $100 \%$ and they are considered as the key explanatory variables in inflation equation. The energy price, money imbalance, money growth and market exchange rate growth have the first to fourth rank respectively. The influence of the production growth is not significant on the inflation in the short-run but it gradually influences the inflation through money imbalance channel in the long-run. In addition, most of the disinflation effects due to decrease in money supply will appear with delay. These results imply the dominance of monetary variables on inflation with cost push factors not having important impacts on prices. Also, oil revenue and imports influence the inflation through exchange rate channel, production and money velocity.
\end{abstract}

Keywords: inflation; Iran economy; Bayesian Model Averaging (BMA)

\section{INTRODUCTION}

The determinants of inflation rate in developing countries are extremely important for policy makers, when the causes of inflation are correctly specified the appropriate policy measures can be effectively implemented ( Amir kia,2006). The main destructive effects of inflation that have considered in most studies include: redistributing revenue in favor of the property owners and the Wage and salary earners losses, increasing uncertainty and macroeconomic instability and thus, shortening the time horizon of decision-making, reduce waste and long-term investments and poor allocation of resources.

In our country with a long history, inflation has the crucial effect on the economic and social sectors and has influenced the vulnerable groups in society. In addition, high levels of inflation rate have increased economic inequalities and have reduced the competitiveness of Iranian goods in world markets.

Changes in inflation can be measured utilizing the consumer price index (CPI) or other appropriate indicators. In experimental and theoretical studies, a very range of variables are considered as determinants of inflation (based on cost and demand push theories). While we 
cannot include all these variables in usual economic analysis methods due to reducing the degree of freedom and uncertainty coefficients, researchers use a limited combination of variables in model based on theory and taste.

However, the problem with the mentioned approach is that the effect of one variable on inflation depends on a combination of other variables that enter the inflation equation. The extensive range of explanatory variables affecting inflation, have suggested the question among researchers what variables should be included in the experimental model of inflation regression. This problem is known as "model uncertainty". One of suitable methods for the problem of model uncertainty is averaging of all models or "Bayesian model averaging (BMA)" (koop, 2003).

The contribution of this paper is using Bayesian econometrics based on Bayesian model averaging in order to overcome the uncertainty in the choice of variables affecting inflation rate and ranking the share of each in Iran economy.

This paper is divided into three sections. Section 2 provides the empirical results of the study and we conclude in section 3 .

\section{DATA AND EMPIRICAL RESULTS}

Both in theoretical and empirical studies, there are many different kinds of variables considered as impressive causes to inflation which reaches up to more than 20 cases. So in this research we apply the method of "Bayesian model averaging" due to variety and kinds of explanatory variables which have been regarded in previous studies.

\section{1. Explanatory variables}

We just consider 13 kinds of variables affecting inflation regarding to limited access to data of variables. The sample data cover the period 1338 - 1391.All the data is obtained from central Bank of Iran, Statistical Center of Iran and Iran`s energy balance sheet. The variables are in terms of growth rate or ratio so that all the variables are stationary (the results of unit root tests for variables are not reported). Some remarks about variables are as follows:

1. In order to measure inflation we have utilized the growth of consuming goods and services index (CPI).

2. Liquidity growth is the most important factor in inflation according to the monetarism theory. Liquidity had been one of growth factors of general prices. According to monetary theory, the resulting effects of liquidity increase does not appear in general prices immediately, however, monetary fluctuations gradually affect the prices during the time. Therefore, lag of liquidity variable is considered in the model in order to control the dynamics of liquidity effect.

3. The monetary imbalance (excess demand and supply of money) is one of the other factors that lead inflation. We call the deviation of money supply in comparison to nominal gross domestic product (GDP) as monetary gap. This gap is measured as a measure of monetary demand or monetary imbalance with lagged Logarithm of the ratio of money to produce.

4. According to the quantitative theory of money, inflation is a function of real revenue. In the current research, the gross domestic product with basic prices $(1376=100)$ used for this purpose.

5. According to the dependency of developing countries such as Iran to oil export revenues, oil revenues variable can affect the inflation through supply (production increase) or demand channels (government spending increase or money supply increase via increasing of currency reserves of central bank) based on structuralists theory and other economy theories. 
6. Wage growth rate, average growth of energy prices, and average rates of interests are chosen as substitute for the cost pressure factors. Also, due to the high dependency of country economy to imports (including consuming, intermediate, and capital imports) growth rate of imported goods price index as well as currency rate used in this model to control the inflation effect of imports.

\section{2. Analyzing "Bayesian averaging model" (BMA)}

One of the most important privileges about BMA analyzing is the high level of trust to coefficients estimated in explanatory variables. Cause these coefficients are not estimated based on just one model but it is derived from model averaging of estimated coefficients in every single variable with 8192 recapitulations or effective samplings. Post mean: the posterior mean of each coefficient (from model averaging) are calculated in this way:

$$
\widehat{\boldsymbol{\beta}}_{\mathbf{1}}=\sum_{t=1}^{I} \lambda_{\boldsymbol{i}} \widehat{\boldsymbol{\beta}}_{1 i}
$$

$\lambda i$ Is the possibility of " $i$ " numbers of model and $\beta 1 i$ is an estimation of $\beta 1$ which is gained in case of Mi model being. Table 1 showing the Post mean, Post Standard Error and the posterior probability.

- Post mean: the posterior mean of each coefficient (from model averaging

- Post Standard Error: the posterior standard deviation of each coefficient (from model averaging)

- posterior probability : the posterior probability that each variable is non-zero (in percent)

Now we are going to analyze regarding to the results of Table 1:

Table 1. The estimation of the inflation equation in Iran by BMA method.

\begin{tabular}{|c|c|c|c|}
\hline Variable & (Post mean) & $\begin{array}{l}\text { Post Standard } \\
\text { error(post sd) }\end{array}$ & (p) \\
\hline Intercept & 0.1103221 & 0.037122 & 100.0 \\
\hline GDP growth & -0.1333481 & 0.171106 & 46.8 \\
\hline Money growth & 0.2733584 & 0.112712 & 96.1 \\
\hline Money growth (t-1) & 0.0234897 & 0.073642 & 16.1 \\
\hline energy price growth & 0.22365142 & 0.059964 & 100.0 \\
\hline $\begin{array}{l}\text { Imported goods price index } \\
\text { growth }\end{array}$ & 0.0281327 & 0.046532 & 35.4 \\
\hline Wage growth & -0.0149823 & 0.045871 & 15.9 \\
\hline Wage growth (t-1) & 0.0016542 & 0.017949 & 3.6 \\
\hline $\begin{array}{l}\text { The Informal exchange rate } \\
\text { growth }\end{array}$ & 0.0882310 & 0.084218 & 65.6 \\
\hline $\begin{array}{l}\text { The official exchange rate } \\
\text { growth }\end{array}$ & 0.0004152 & 0.003495 & 4.1 \\
\hline $\begin{array}{l}\text { Monetary Imbalance index } \\
(\mathrm{t}-1)\end{array}$ & 0.081008 & 0.024147 & 100.0 \\
\hline Goods import growth & 0.00029781 & 0.0085126 & 2.2 \\
\hline Interest rate & 0.0005012 & 0.0094853 & 2.1 \\
\hline Oil revenue growth & 0.01232181 & 0.032004 & 20.6 \\
\hline
\end{tabular}


Second column on the right hand is the latest weight mean of the coefficients of each variable, the 3rd column is the error of the latest distribution criterion of the coefficients and the 4th column is the probability of occurrence of any of the variables in 8192 times of effective sampling of the models. In consideration of the column of the probability of occurrence of each descriptive variable, we may find out that, among the descriptive variables in question, some variables may affect the inflation (there is a certain probability of the same on the inflation model). Results of the Table 1 may be explained as follows:

- The energy price growth and monetary imbalance in previous period (lagged Logarithm of the ratio of money to nominal produce) had positive and certain effect on the inflation with $100 \%$ probability. The weighted average of mentioned variables coefficient are 0.22 and 0.08 , respectively, with low standard errors of 0.05 and 0.02 , respectively. Therefore, money supply growth with respect to production and price growth in previous period has important effects on the current period inflation. The pivotal effect of energy price growth on inflation may be due to the strong synchronization (statistically) between these two variables and necessarily, whole of it cannot be related to the strong effects of energy prices on the inflation in Iran's economy.

- The ratio of money to production is considered in the model as an measure of monetary excess or monetary imbalance. According to its certain impact on the inflation, such result reveals that the inflation in Iran's economy is monetary. Among them, lagged money supply growth has not an important impact on the inflation with the low probability of $16.1 \%$. Thus, the money supply growth effects are wiped out in the same year or period and only with imbalance between money supply and production, this excess money is transferred to the next period as inflation.

- The money supply growth variable in current period with the probability of $96.1 \%$ is the other important variable that positively and almost certainly affected the inflation, so that based on the obtained results the post mean of this variable in impact on inflation is around 0.27 . It seems that money supply growth does not increase the prices proportionally in that period (short term). But the created imbalance between money supply and demand gradually is overflowed on prices during the time. The aforementioned result is at least in consistence with money dependency in some parts of Iran's economy. Based on the monetary theories, money supply growth in economy results in transfer of total demand and if the demand and production was lower than its supply, prices will increase until the elimination of excess cash properties.

- The currency rate growth in free market is the fourth effective variable on inflation with the probability of $65.6 \%$ and has a positive and important impact on it. On the other hand, growth of imported goods price measure (wholesale) leaves less impact on the inflation with the probability of $35.4 \%$. Therefore, it seems that consumer price has closer links with currency rate in free market rather than wholesale imported prices. This result seems logical considering that wholesale imported prices were severely controlled in some sample periods.

- The growth rate of gross domestic production (GDP) has a negative coefficient and with probability of $46.8 \%$ is the fifth effective factor on inflation growth in Iran's economy. The production increase can compensate some parts of inflation impacts. On average, per each one percent production growth, inflation rate decreases $0.13 \%$. Anyway, its lower rating rather than price variables, shows the denoting of the dominance of monetary variables and low destitute of supply related factors on monetary fluctuations in short term period. Additionally, the production growth through monetary imbalance of previous period (money to production ratio) channel is significantly affecting the inflation. Therefore, it seems that this variable still has long term effects on the inflation. 
- The oil revenue growth with the probability of $20.6 \%$ and coefficient of 0.012 has positive but negligible impact on the inflation in the Iran's economy. Therefore, the oil revenue growth only through monetary and real variables can affect the inflation and its impact on the inflation after controlling the aforementioned factors is negligible. The growth of goods import also has negligible impact on the inflation and only through other variable channels (probably currency and production rate) may affect the inflation.

- The wages growth with probability of $15.9 \%$ and coefficient of -0.014 has also negative and insignificant impact on the inflation. The other variables including wage growth in the previous period, growth of official currency rate, growth of goods import and growth of interest rate have not any impact on the Iran's economy based on their low probabilities. Thus, it seems that cost pressure factors were not able to explain the price fluctuations during the sample period.

\section{3. Selection of Optimal Models}

After selection of model under BMA method, we may extract 5 first models, which may be of the highest level of inclusion probability, respectively. The latest probability of each model may be calculated in accordance with the following equation on the basis of Bayes Rule (by the application of R Software):

$$
P\left(M_{i} \mid y\right)=\frac{p\left(y \mid M_{i}\right) p\left(M_{i}\right)}{p(y)}
$$

The results of estimate of the most probable models ( 5 most possible models) are shown in the Table 2. The second row from the lower part in the Table 2, shows the BIC (Bayesian Information Criterion) of each model. Such a criterion is generally applied for selection of the optimum model. The lower the rate of the mentioned criterion or the higher the rate of absolute value, the model in question is placed in a higher rank from the point of view of fit and simplicity. The first model with the Bayesian Information Criterion BIC of -48.92154 is considered as the best model. The last row in the Table 2 shows the determination coefficient of each model. As the descriptive variables of each model are different, therefore, the determination coefficient of the models is not an appropriate criterion for selection from among them.

Table 2. Five optimal model.

\begin{tabular}{|c|c|c|c|c|c|}
\hline \multicolumn{1}{|c|}{ models } & $\begin{array}{c}\text { The first } \\
\text { model }\end{array}$ & $\begin{array}{c}\text { The } \\
\text { second } \\
\text { model }\end{array}$ & $\begin{array}{c}\text { The third } \\
\text { model }\end{array}$ & $\begin{array}{c}\text { The } \\
\text { fourth } \\
\text { model }\end{array}$ & $\begin{array}{c}\text { The fifth } \\
\text { model }\end{array}$ \\
\hline Intercept & 0.10284 & 0.13824 & 0.08722 & 0.11246 & 0.14842 \\
\hline GDP growth & 0 & -0.24863 & 0 & -0.17189 & 0 \\
\hline Money growth & 0.30248 & 0.27986 & 0.27777 & 0.32041 & 0.25123 \\
\hline Money growth(t-1) & 0 & 0 & 0 & 0 & 0 \\
\hline energy price growth & 0.23003 & 0.25111 & 0.20048 & 0.22843 & 0.27039 \\
\hline Imported goods price growth & 0 & 0 & 0.07361 & 0 & 0 \\
\hline Wage growth & 0 & 0 & 0 & 0 & 0 \\
\hline Lagged Wage growth & 0 & 0 & 0 & 0 & 0 \\
\hline
\end{tabular}




\begin{tabular}{|c|c|c|c|c|c||}
\hline The official exchange rate growth & 0 & 0 & 0 & 0 & 0 \\
\hline Lagged logarithm of money to GDP & 0.08412 & 0.09234 & 0.075774 & 0.08924 & 0.1005 \\
\hline Goods import growth & 0 & 0 & 0 & 0 & 0 \\
\hline Interest rate & 0 & 0 & 0 & 0 & 0 \\
\hline Oil revenue growth & 0 & 0 & 0 & 0 & 0 \\
\hline P & 0.121 & 0.109 & 0.08 & 0.061 & 0.049 \\
\hline BIC & -48.92154 & -48.71227 & -47.86428 & -47.12384 & -46.6624 \\
\hline $\mathbf{R}^{2}$ & 0.745 & 0.741 & 0.762 & 0.781 & 0.707 \\
\hline
\end{tabular}

\section{CONCLUSIONS}

The macroeconomic policies emphasize on goals such as full employment, price stability, appropriate income distribution, and sustainable economic growth. Therefore, studying the determinants of inflation and the importance of each variable in Iran's economy is of great importance for policy makers.

We used Bayesian averaging method by $\mathrm{R}$ software to study the effect of 13 variables on the inflation of Iran's economy. In this method all of possible sub-models $\left(2^{13}\right.$ equivalent to 8192 models) are estimated. Then, the coefficient of each variable is averaged in all models. The weights in this averaging are defined based on Bayes. The growth of consumer price index (CPI) variable is used as dependent variable in the current study. The money to production ratio is considered as a criterion of monetary excess or imbalance. The results confirm that energy price growth and lagged logarithm of the money to production (monetary imbalance) have positive and certain impact on the inflation with the probability of $100 \%$. The weighted average of coefficient are 0.22 and 0.08 , respectively, with low standard errors of 0.05 and 0.02 , respectively.

The money supply growth variable in current period with the probability of $96.1 \%$ is the other important variable that positively and almost certainly affected the inflation. Among them, lagged money growth has not an important impact on the inflation having the low probability of $16.1 \%$. Therefore, the delayed effects of money on the inflation are controlled through monetary imbalance channel of previous period. Indeed, the inflation rate is adjusted in the next period to reduce the monetary gap following monetary imbalance (monetary excess is transferred to the next period into higher inflation). Actually, the most part of antiinflation effects caused by reduction of money supply in Iran's economy is not depleted but its impact is appeared with delay. Such results confirm the monetary nature of inflation in Iran's economy.

The currency rate growth in free market is the fourth effective variable on inflation with the probability of $65.6 \%$ and has a positive and important impact on it. On the other hand, growth of imported goods price index (wholesale) leaves less impact on the inflation with the probability of $35.4 \%$. Therefore, it seems that consumer price index has closer links with currency rate in free market rather than wholesale imported prices. This result seems logical considering that wholesale imported prices were severely controlled in some sample periods. Additionally, a lot of issues of imported price changes by currency rate are explained.

Although the production growth with the probability of $46.8 \%$ and coefficient of -0.13 has the expected sign, has not strong direct impact on the inflation in short time. But this variable still affects the inflation gradually through monetary imbalance channel with a delay. The other under studying variables, are in the next rankings of impact on the inflation and have not important impact on the inflation fluctuations in Iran's economy. The oil revenue 
and imports growth has negligible impact on the Iran's economy with the probability of $20.6 \%$ and $2.2 \%$, respectively. The aforementioned results show that major part of oil revenues (or imports) on the inflation is come from monetary variables channel, currency rate, and production growth. The oil revenues had not independent impact on the inflation in Iran's economy after controlling the aforementioned variables. Additionally, cost pressure factors such as wages and banking interest rate have not important impact on the inflation.

According to the findings of current research, the most important effective factors on the inflation in the Iran's economy are monetary imbalance, money supply growth, and growth of energy price. Additionally, it is expected that the price increase of energy increase the inflation through production cost and provoking the inflation expectations. Therefore, controlling the inflation expectations specially through controlling the price of energy, general services, and simultaneously contractionary monetary policies seem to be necessary to reduce the inflation.

\section{References}

[1] Adusei, M. (2013). Is Inflation in South Africa a Structural or Monetary Phenomenon?. British Journal of Economics. Management \& Trade 3(1); 60-72.

[2] Altowaijri, H \& A (2009). .External and Internal Determinants of Inflation: A Case study of Saudi Arabia. Middle East Journal of Economics and Finance 2(1), 25-38.

[3] Danilov, D., Magnus, J.R (2004). On the harm that ignoring pretesting can cause. Journal of Econometrics 122(5), 27-46.

[4] Feldere, B. \& Hamburg, S. (1920). Macroeconomics. Berlin: Springer-Verlage.

[5] Fern'andez, C., E. Ley, and M. F. J. Steel (2001). Model uncertainty in cross-country growth regressions. Journal of Applied Econometrics 16(3), 563-576.

[6] Friedman, M (1970). The counter-revolution in monetary theory; London, pp24.

[7] Hagger, A. (1977). Inflation, Theory and Policy (First Ed). London: Macmillan press.

[8] Koop, Gary (2003). Bayesian Econometrics. John Wiley \& Sons Ltd,England.

[9] Lindsey C., Sheather S. (2010).Variable selection in linear regression. The Stata Journal $10(4), 650-669$.

[10] Liu O., Olumuyiwa S. Adedji, Determinants of inflation in Islamic Republic of Iran. IMF Working Paper, wp/00/127.

[11] Loungani, P., Swagel, P "Sources of inflation in Developing Countries ". IMF Working Paper, wp/01/19.

[12] Lucas, R. E. J (1973). Some international evidence on output-inflation trade -offs. American Economic Review 63(3), 326-334.

[13] Magnus, J. R., O. Powell \&P. Prufer( 2010). A comparison of two model averaging techniques with an application to growth empirics. Journal of Econometrics 154(5), 139-153.

[14] Magnus, J.R. \& Wang, W. (2012) Concept-Based Bayesian Model Averaging and Growth Empirics. Center Discussion Paper Series No. 20122-017. 
[15] Masanjala, W., Papageorgiou, C. (2008). Rough and lonely road to prosperity: A reexamination of the sources of growth in Africa using Bayesian model averaging. Journal of Applied Econometrics 23(7), 671-682.

[16] Poirier, D. (1995) Intermediate Statistics and Econometrics: A Comparative Approach. Cambridge: The MIT Press.

[17] Raftery, A.E. (1995). Bayesian model selection in social research. Sociological Methodology, 25(4), 111-163.

[18] Sargent, T. J. \& Wallace, N. (1975). Rational Expectations, the Optimal Monetary Instrument and the Optimal Money Supply Rule. Journal of Political Economy, 83(2), 241-254

[19] Zellner, A. (1986). On assessing prior distributions and Bayesian regression analysis with g-prior distributions. In Bayesian Inference and Decision Techniques: Essays in Honor of Bruno de Finetti, ed. P. K. Goel and A. Zellner, 233-243. 